\title{
Pengaruh Pelatihan Otonomi terhadap Tingkat Otonomi Siswa Sekolah Menengah Atas di Bandung
}

\author{
Sulisworo Kusdiyati, Yuli Aslamawati, Dwi Agustin Nuraini Sirodj \\ Universitas Islam Bandung, Jl. Tamansari No.1 Bandung 40116. \\ e-mail: sulisworo.kusdiyati@gmail.com
}

\begin{abstract}
High school students in the city of Bandung appeared to have moderate or even low learning engagement. This low level of learning engagement was caused by low sense of autonomy. Therefore, to increase learning engagement, an autonomy training program is needed for these students. This study aimed to find out whether the autonomy training program increases the autonomy level of students. The design of the study was quasi-experimental with the one-group before-after design. The research subjects were collected using random sampling technique, with a total of 37 students from two high schools in Bandung. The Autonomy instrument was collected using a questionnaire compiled by researchers based on Ryan and Deci's Self-determination theory. Based on the validity and reliability test, the instrument was valid and reliable. The results showed that autonomy training is effective in enhancing students' sense of autonomy.
\end{abstract}

Keywords: autonomy, autonomy training, senior high school

\begin{abstract}
Abstrak
Penelitian terhadap siswa-siswa SMA di kota Bandung memberikan hasil bahwa keterlibatan belajar siswa tergolong sedang bahkan ada yang rendah. Faktor penting yang menyebabkan hal tersebut adalah sense of autonomy yang juga tergolong sedang dan rendah. Oleh karena itu guna meningkatkan keterlibatan belajar perlu dilaksanakan program pelatihan autonomy terhadap siswa-siswa tersebut. Penelitian ini bertujuan untuk menguji apakah program pelatihan otonomi meningkatkan tingkat otonomi siswa. Rancangan penelitian ini adalah kuasi eksperimen dengan desain one-group before-after. Subjek penelitian diambil sebagai sampel dengan teknik random sampling, dan diperoleh sebanyak 37 siswa dari dua SMA di Bandung. Instrumen otonomi dijaring menggunakan kuesioner yang disusun berdasarkan self-determination theory dari Ryan dan Deci. Hasil penelitian menunjukkan bahwa pelatihan otonomi efektif dalam meningkatkan sense of autonomy siswa.
\end{abstract}

Kata Kunci: otonomi, pelatihan otonomi, siswa sekolah menengah atas

\section{Pendahuluan}

Nilai Indeks Pengembangan Manusia Indonesia adalah .629 dan termasuk dalam kategori medium human development dan ini menyebabkan Indonesia meraih peringkat ke-121 dari 186 negara dan 8 negara-teritori (Human Development Report, 2013). Di Jawa Barat kuali-tas sumber daya manusia yang rendah disebabkan karena nilai partisipasi dan pencapaian pendidikan yang rendah (BPS, 2014). Di Bandung, jumlah siswa SMA merupakan jumlah terbanyak dibandingkan dengan kota-kota lain di Jawa Barat, tetapi nilai APK (Angka Partisipasi Kasar) dan nilai APM (Angka Partisipasi Murni) lebih rendah daripada kota-kota lain di Jawa Barat (BPS, 2014). Penelitian yang dilakukan Halimah, Kusdiyati, dan Susandari (2017) mengenai keterlibatan belajar siswa SMA di kota Bandung memberikan hasil bahwa mayoritas keterlibatan belajar siswa SMA berada dalam kategori sedang bahkan ada yang rendah. Dari penelitian tersebut juga terungkap bahwa ada pengaruh konteks teman sebaya terhadap keterlibatan belajar melalui self-system processes (sense of relatedness, sense of autonomy, sense of competence). Self-system processes yang memiliki korelasi terbesar dengan keterli- 
batan belajar adalah sense of autonomy (Halimah dkk., 2017).

Adapun tingkat sense of autonomy siswa SMA yang diteliti mayoritas berada dalam kategori sedang bahkan ada yang rendah. Artinya dalam melakukan aktivitas belajar siswa belum sepenuhnya didorong oleh adanya nilai dan tujuan personal, namun masih disebabkan oleh orang lain (karena ingin mendapat nilai bagus, ada dorongan dari teman sebaya, adanya reward lain dari teman sebaya). Dengan kata lain dalam melakukan aktivitas belajar mayoritas siswa belum ditentukan oleh diri sendiri atau sense of autonomy (Halimah dkk., 2017). Untuk meningkatkan sense of autonomy siswa, perlu diadakan program intervensi berupa pelatihan otonomi agar nantinya ketelibatan belajar siswa dapat meningkat.

Penelitian-penelitian terdahulu mengenai intervensi untuk meningkatkan sense of autonomy siswa dilakukan dengan melakukan intervensi terhadap guru agar guru dalam mengajar mendukung otonomi siswa dengan cara meningkatkan self-efficacy guru dan tujuan instruksional intrinsik (Cheon, Reeve, Lee, \& Lee, 2018); intervensi terhadap guru untuk menjalankan self-determined learning model of instruction di kelas (Wehmeyer \& Shogren, 2016). Meta-analisis yang dilakukan oleh Su dan Reeve (2011) bahwa intervensi untuk meningkatkan autonomy diberikan kepada guru, guru olah raga atau trainer agar guru, guru olahraga memberikan autonomy support kepada siswanya ketika mengajar di kelas. Penelitian yang dilakukan Cheon, Reeve, dan Song (2016) bahwa intervensi terhadap guru dilakukan agar guru memberikan autonomy support terhadap siswa yang berada dalam kategori amotivation. Dari penelitian-penelitian di atas tampak bahwa sasaran intervensi adalah guru. Peneliti meneliti dengan memberikan program intervensi berupa pelatihan terhadap siswa SMA agar siswa dapat menunjukkan autonomy dalam belajar. Intervensi diberikan kepada siswa meng- ingat siswa SMA yang berada pada tahap perkembangan remaja sedang berjuang untuk mencapai autonomy atau kemandirian dari orang tua dan belajar membuat keputusan sendiri mengenai hal-hal yang berkaitan dengan kehidupannya (Spear \& Kulbok, 2004; Berk, 1998). Oleh karena itu peneliti tertarik untuk melakukan penelitian yang bertujuan untuk mendapatkan data empiris mengenai pengaruh pelatihan otonomi terhadap tingkat otonomi pada siswa SMA di kota Bandung.

Training atau pelatihan adalah setiap aktivitas yang direncanakan untuk mentransfer atau memodifikasi atau mengubah pengetahuan, keterampilan (skill), dan sikap (attitude) melalui pengalaman belajar (Management Science for Health, 2012). Adapun menurut Wexley, Sanders, dan Yukel (1973), pelatihan atau training adalah proses mengubah sikap-sikap yang terintegrasi dengan kehidupan, pekerjaan dan perkembangan diri. Termasuk dalam hal ini adalah perubahan dalam pengetahuan (aspek kognisi), perasaan (aspek afektif) dan aspek psikomotor atau perilaku. Pelatihan otonomi dimaksudkan untuk mengubah kemampuan siswa yang tidak otonom dalam menentukan aktivitas belajar menjadi otonom dalam mengarahkan aktivitas belajarnya.

Pengertian autonomy yang dikemukakan oleh Ryan dan Deci (2002) menunjuk kepada persepsi seseorang bahwa dirinya menjadi asal atau sumber perilakunya sendiri. Autonomy adalah kebutuhan dasar psikologis penting yang menunjukkan pengalaman mengarahkan diri sendiri dalam berpikir, berperasaan dan bertindak (Legault, 2016). Autonomy menunjuk kepada persepsi bahwa seseorang memerintah dirinya sendiri untuk berperilaku daripada dikendalikan oleh kekuatan dari luar (Legault, 2016). Ketika seseorang merasa otonom maka ia menilai kebutuhankebutuhannya, motivasi-motivasinya, kesukaannya akan sesuatu, dan perilakunya tidak dapat dipisahkan dan kongruen satu sama lain (Legault, 2016). 
Teori yang digunakan dalam penelitian ini adalah self-determination theory dari Ryan dan Deci. Self-determination theory adalah sebuah pendekatan motivasi dan kepribadian yang menyoroti pentingnya sumber daya manusia untuk pengembangan kepribadian dan perilaku yang diregulasi oleh diri sendiri. Teori ini berawal dari kumpulan asumsi bahwa semua individu memiliki kecenderungan alami, bawaan dan konstruktif untuk mengembangkan sense of self yang rumit dan terpadu (Ryan \& Deci, 2002). Berdasar pada asumsi di atas, SDT memiliki pendekatan organismic dialectical, yaitu bahwa individu adalah organisme yang aktif, memiliki kecenderungan untuk tumbuh, menguasai lingkungan yang menantang dan mengintegrasikan pengalaman baru ke dalam kesatuan dirinya (Ryan dan Deci, 2000; 2002).

Self-determination melekat dalam kegiatan yang didasari oleh motivasi intrinsik untuk kepentingan diri sendiri (Assor, Roth, \& Deci, 2004). Menurut Ryan dan Deci (2000) motivasi bukanlah fenomena unitary. Artinya, seseorang tidak saja memiliki jumlah atau kekuatan motivasi yang berbeda dengan orang lain, tetapi juga memiliki jenis dan orientasi motivasi yang berbeda. Orientasi motivasi memunculkan sikap dan tujuan sebagai dasar dari tindakan. Hal ini menjelaskan mengapa seseorang melakukan tindakan atau perilaku tertentu.

Selanjutnya Ryan dan Deci (2000), menyatakan bahwa dalam self-determination theory (SDT) dikaji jenis atau tipe motivasi berdasarkan alasan atau tujuan dari suatu tindakan atau perilaku. Terdapat 3 tipe motivasi yang merupakan suatu kontinum yaitu amotivation, extrinsic motivation, dan intrinsic motivation (Ryan \& Deci, 2002). Ketika berbicara tentang motivasi, di dalamnya terdapat tipe-tipe regulasi atau regulation style. Amotivation adalah keadaan dimana tidak ada regulasi diri (Ryan \& Deci, 2002). Amotivation, yang merupakan keadaan dimana seseorang kurang memiliki niat untuk bertindak.
Ketika termotivasi, perilaku seseorang tidak memiliki intensionalitas dan rasa penyebab pribadi. Amotivasi hasil dari tidak menilai aktivitas, tidak merasa kompeten untuk melakukannya, atau tidak percaya hal itu akan menghasilkan hasil yang diinginkan (Ryan \& Deci, 2000).

Adapun extrinsic motivation merupakan suatu kontinum yang bergerak dari external regulation, kemudian introjected regulation, lalu identified regulation, menuju integrated regulation (Ryan \& Deci, 2002). External regulation adalah bentuk extrinsic motivation yang paling minim otonomi, dimana seseorang melakukan aktivitas belajar dimotivasi untuk mendapatkan ganjaran atau menghindari hukuman dari lingkungan (Ryan \& Deci, 2000; 2002). Secara umum dapat dikatakan bahwa alasan seorang siswa melakukan aktivitas belajar adalah untuk memuaskan tuntutan dari lingkungan.

Introjected regulation adalah regulasi eksternal yang telah diinternalisasi namun tidak terlalu dalam, hanya diterima sebagai bagian dari individu, dikatakan hanya sebagian diinternalisasi dalam diri individu namun belum menjadi terintegrasi dalam dirinya (Ryan \& Deci, 2000; 2002). Perilaku aktivitas belajar yang didasari introjected regulation ditampilkan dengan tujuan untuk menghindari rasa bersalah dan rasa malu (Ryan \& Deci, 2000; 2002) atau untuk mendapatkan peningkatan ego dan perasaan berharga (Ryan \& Deci, 2002) atau mendapatkan ganjaran dan menghindari hukuman internal (Ryan \& Deci, 2000).

Identified regulation adalah bentuk extrinsic motivation yang lebih ditentukan oleh diri sendiri dimana terdapat kesadaran mengenai pentingnya mencapai tujuan, (Ryan \& Deci, 2002), siswa melakukan aktivitas belajar karena aktivitas tersebut secara personal penting bagi dirinya ( Ryan \& Deci, 2000; 2002). Disini ada proses mentransformasi regulasi eksternal ke dalam self-regulation yang sesungguhnya. Artinya tingkat otonominya semakin tinggi. 


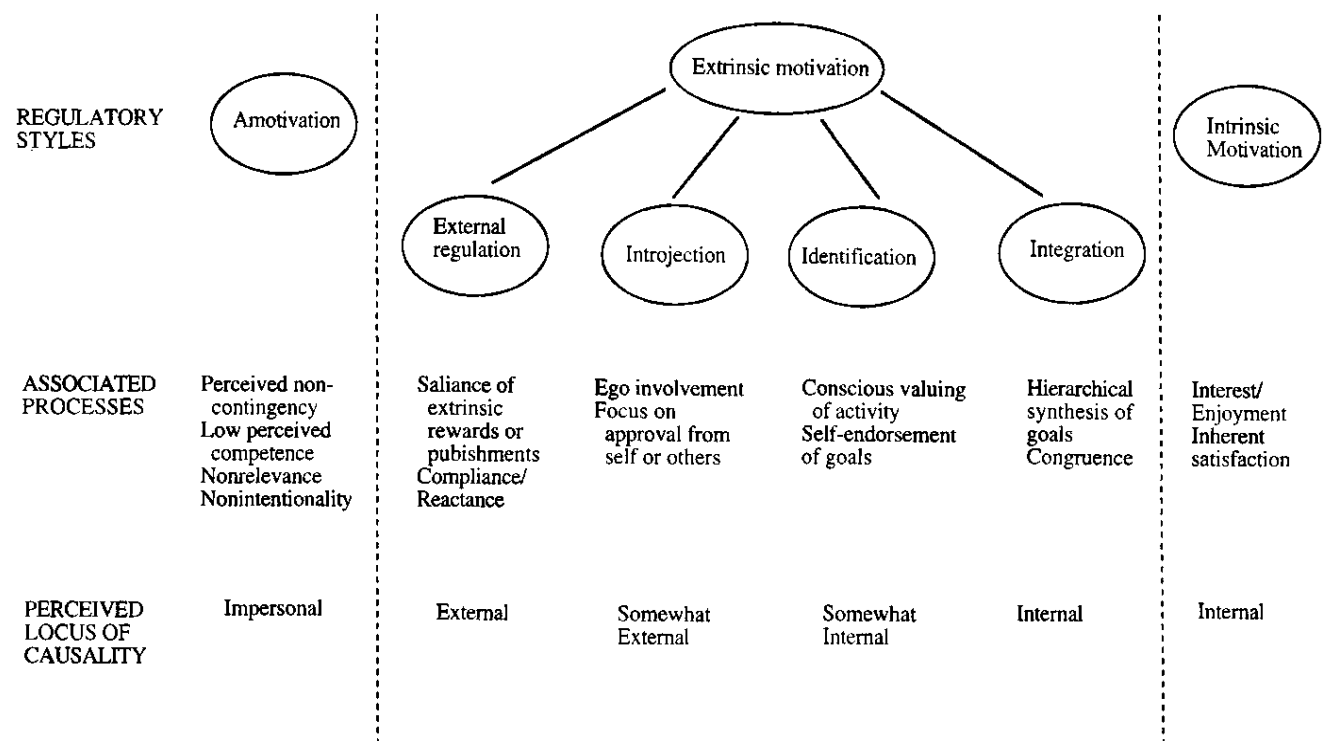

Gambar 1. Taksonomi motivasi manusia

Integrated regulation adalah bentuk regulasi yang paling otonom atau bentuk extrinsic motivation yang paling otonom (Ryan \& Deci, 2002). Siswa melakukan aktivitas belajar karena adanya kesadaran, kongruensi dan sintesis dengan self (Ryan $\&$ Deci, 2000).

Intrinsic motivation adalah suatu keadaan termotivasi, dimana seseorang melakukan suatu aktivitas untuk mendapatkan kepuasan yang melekat pada aktivitas tersebut (Ryan \& Deci, 2000). Artinya siswa melakukan aktivitas belajar karena ia berminat, senang mengerjakannya, menikmati dalam mengerjakannya atau merasa tertantang untuk mengerjakannya sehingga ia lekat dan enggan melepaskan diri dari aktivitas tersebut (Ryan \& Deci, 2000). Konsep ini diterima dan dijadikan rujukan penting dalam dunia pendidikan.

Program pelatihan otonomi dalam penelitian ini secara umum disusun untuk mengubah siswa yang tadinya dalam beraktivitas belajar tidak termotivasi, atau harus ada dorongan dari luar menjadi beraktivitas belajar atas keinginan sendiri. Pelatihan otonomi ini terbagi menjadi dua bagian besar yaitu assessment diri dan proses pelatihan otonomi itu sendiri.

Adapun tujuan pelatihan otonomi adalah: (1) mengarahkan siswa untuk terlibat penuh dalam aktivitas untuk berubah menjadi lebih otonom; (2) memberikan kesadaran pada siswa bahwa untuk berubah menjadi lebih otonom diperlukan persiapan; (3) memberikan pengalaman simulasi perubahan melalui permainan (games), dimana siswa harus terbuka dan siap untuk melakukan perubahan, bahwa dalam proses perubahan menjadi otonom siswa akan menghadapi kesulitan namun siswa harus memahami bahwa setiap kesulitan akan bisa diatasi apabila siswa berpikir fleksibel dan thinking out of the box, bahwa perubahan harus dimulai dari diri siswa sendiri; (4) memberikan pengalaman simulasi autonomy melalui permainan/ games, agar siswa menyadari bahwa siswalah yang menentukan pilihan untuk bertindak kreatif, siswalah yang menentukan pilihan cara penyelesaian masalah bukan orang lain, dan dalam penyelesaian masalah ada pengorbanan, dalam setiap keberhasilan dalam permainan/games ada keyakinan akan kemampuan diri sendiri; (5) memberikan pengalaman simulasi komitmen agar siswa dapat membangun komitmen untuk berubah menjadi individu yang adaptif, tekun, terus mencoba dan berusaha melalui sikap positif serta menyadarkan siswa akan pentingnya keyakinan dan tekad yang bulat untuk pengalaman 
sukses dan perasaan positif tentang suatu kegiatan; (6) memberikan pemahaman pada siswa bahwa ia mampu berubah menjadi individu yang lebih otonom dalam pembelajaran.

\section{Metode Penelitian}

\section{Rancangan Penelitian}

Penelitian ini menggunakan rancangan penelitian kuasi eksperimen, dengan rancangan one-group design before-after. Dengan desain ini ingin dianalisis apakah ada pengaruh pelatihan otonomi terhadap tingkat otonomi. Desain ini dipilih dengan alasan karena peserta pelatihan jumlahnya terbatas. Adapun skema desain penelitian disajikan pada gambar 1. Variabel bebas dalam penelitian ini adalah program pelatihan otonomi. Adapun variabel dependen adalah tingkat otonomi.

\begin{tabular}{|cccc|}
\hline Group & $\begin{array}{c}\text { Before } \\
\text { Observation }\end{array}$ & Treatment & $\begin{array}{c}\text { After } \\
\text { Observation }\end{array}$ \\
1 & $\mathrm{~W}$ & $\mathrm{X}$ & $\mathrm{Y}$ \\
\hline
\end{tabular}

Gambar 2. Skema one group design before-after

Keterangan:

W : Pengukuran awal sebelum diberikan treatment

$\mathrm{X}$ : Pemberian treatment berupa pelatihan otonomi

Y : Pengukuran akhir setelah diberikan treatment

\section{Subjek Penelitian}

Dalam penelitian ini, teknik sampling yang digunakan adalah random sampling. Peneliti mengambil 2 sekolah dari sekolahsekolah yang dijadikan sampel penelitian pada tahun 2017 secara random. Sekolah yang terpilih untuk dilakukan program intervensi sense of autonomy adalah SMA Negeri 6 dan SMA Negeri 17. Dari masingmasing sekolah dipilih sekitar 20-25 siswa secara random. Adapun karakteristik sampel adalah: 1) Siswa yang bermasalah (prestasi rendah, pernah bolos); 2) Kategori sense of autonomy tergolong sedang atau rendah; 3) Kategori keterlibatan belajar tergolong sedang atau rendah.

Tabel 1

Sampel Penelitian

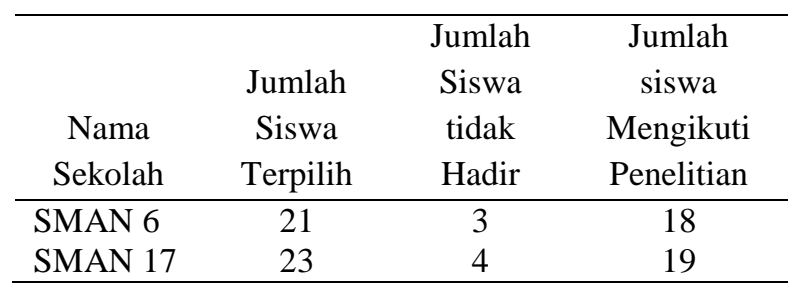

Berdasarkan tabel 1 dapat dilihat bahwa terdapat siswa yang tidak hadir pada saat pretest dan posttest di SMAN 6. Siswa yang bersangkutan merupakan atlet yang sedang melakukan latihan untuk suatu kejuaraan olah raga. Adapun siswa di SMAN 17 yang tidak hadir disebabkan alasan sakit.

\section{Prosedur Penelitian}

Prosedur penelitian terhadap siswa dari dua sekolah dilakukan secara terpisah. Kegiatannya terdiri atas 4 pertemuan untuk setiap sekolah, yaitu: (1) pelaksanaan psikotes untuk mengetahui bakat dan minat siswa (menggunakan IST, WZT, Baum, DAM, tes Holland, dan tes Pauli), dan pemberian pretest yang terdiri dari kuesioner sense of autonomy serta kuesioner keterlibatan belajar; (2) konsultasi hasil psikotes kepada siswa secara individual oleh psikolog; (3) kegiatan pelatihan otonomi yang berlangsung sekitar 4 sampai 5 jam; (4) pemberian posttest dengan kuesioner sense of autonomy dalam waktu 8 hari/satu minggu setelah pelatihan.

Kegiatan pelatihan dilaksanakan dalam 12 sesi dengan waktu 4 sampai 5 jam, menggunakan fasilitas ruang kelas, alat tulis berupa ballpoint, pensil, spidol dan kertas, whiteboard, laptop, infocus/ LED, mic; fasilitas kerja/ pelatihan: snack/ coffee break dan makan siang. Metode pelatihan berupa ceramah, pemutaran film, diskusi, dan games.

Kegiatan pelatihan diawali dengan ice breaking selama 10 menit yang diikuti oleh semua peserta, dengan metode per- 
mainan/ games "tangkap tangan teman". Kegiatan ini bertujuan agar siswa lebih nyaman, lebih terbuka dan mau terlibat secara penuh dalam mengikuti kegiatan.

Sesi 1. Tes Instruksi selama 10 menit, tujuan sesi 1 adalah siswa diarahkan agar adaptif dan menunjukkan keterlibatan penuh dalam belajar. Metode yang dipakai adalah permainan dan diskusi.

Sesi 2. Menonton cuplikan film, yang menyiratkan pentingnya sebuah persiapan. Tujuan sesi 2 adalah memunculkan kesadaran pada siswa mengenai pentingnya persiapan secara mental untuk melakukan suatu tugas. Kegiatan ini berlangsung selama 10 menit.

Sesi 3. Simulasi Perubahan 1 dengan menggambar pemandangan selama 20 menit. Tujuan sesi 3 adalah siswa memiliki keterbukaan dan kesiapan diri untuk melakukan perubahan melalui tugas yang sederhana. Metode adalah menggambar dan diskusi.

Sesi 4. Simulasi Perubahan 2, menyambungkan 9 titik. Tujuan sesi 4 adalah siswa memiliki keterbukaan dan kesiapan diri untuk melakukan perubahan melalui tugas yang lebih kompleks, dan siswa menyadari bahwa setiap kesulitan selalu ada cara untuk mengatasinya, siswa diharapkan, dapat berpikir fleksibel, thinking out of the box. Kegiatan ini dilaksanakan selama 15 menit.

Sesi 5. Simulasi Perubahan 3, "Siapa saya". Tujuan sesi 5 adalah membuat siswa menyadari bahwa perubahan harus dimulai dari pikiran sendiri. Metode yang digunakan adalah siswa menjelaskan kepada teman sekelompok mengenai "siapa saya". Kegiatan berlangsung selama 15 menit.

Sesi 6. Simulasi Otonomi 1, permainan bola selama 15 menit. Tujuan sesi 6 adalah membuat siswa menyadari harus menentukan pilihan dan/atau menggunakan peluang untuk bertindak kreatif serta pemahaman bahwa keberhasilan dalam permainan/games akan memberikan keyakinan akan kemampuan diri. Metode berupa games.

Sesi 7. Simulasi Otonomi 2, games "Everybody Stand Up" selama 20 menit. Tujuan sesi 7 adalah berlatih untuk menentukan pilihan dalam menyelesaikan masalah, serta keberhasilan dalam permainan menyiratkan adanya pengakuan kemampuan untuk pengarahan diri sendiri dan orang lain. Metode berupa games/ permainan.

Sesi 8. Simulasi Otonomi 3, games "Hands Note" selama 45 menit. Tujuan sesi 8 adalah melatih kesadaran siswa bahwa menyelesaikan masalah membutuhkan pengorbanan serta efektivitas menentukan pilihan tindakan/pengorbanan menyiratkan adanya pengakuan akan kemampuan untuk pengarahan diri sendiri. Metode berupa games yaitu permainan tali dimana siswa harus menguraikan tali yang kusut di tangannya tanpa melepaskan ikatannya.

Sesi 9. Simulasi Otonomi 4, jingle iklan selama 60 menit. Tujuan sesi 9 adalah melatih siswa tentang cara mengekspresikan diri, memunculkan potensi dan nilai-nilai diri. Metode yaitu penyelesaian tugas membuat jingle iklan berdurasi 5 menit, dengan syarat minimal melalui tarian dan nyanyian.

Sesi 10. Simulasi Komitmen 1, menulis dengan tangan kanan dan tangan kiri, berlangsung selama 30 menit. Tujuan sesi 10 adalah membangun komitmen siswa untuk berubah menjadi individu yang adaptif, tekun, terus mencoba dan berusaha melalui sikap positif. Metode berupa games menulis kata dengan tangan kanan dan tangan kiri.

Sesi 11. Simulasi Komitmen 2, games "Patah Pensil" selama 15 menit. Tujuan sesi 11 adalah menyadarkan siswa akan pentingnya keyakinan dan tekad yang bulat untuk pengalaman sukses dan perasaan positif tentang suatu kegiatan. Metode berupa games mematahkan pensil hanya dengan satu jari. 
Sesi 12. Review selama 20 menit.. Tujuan sesi 12 adalah proses pemahaman dan internalisasi nilai-nilai baru sebagai dasar keterlibatan dalam pembelajaran. Metode berupa pembahasan seluruh rangkaian kegiatan.

\section{Pengumpulan Data dan Alat Ukur}

Metode pengumpulan data yang digunakan adalah kuesioner. Alat ukur sense of autonomy berbentuk skala, dengan 4 alternatif jawaban yaitu sangat tidak sesuai (STS), tidak sesuai (TS), sesuai (S) dan sangat sesuai (SS).

Adapun prosedur pembuatan alat ukur adalah peneliti membuat kisi-kisi alat ukur yang memuat definisi konseptual, definisi operasional, aspek dan indikator, dari indikator kemudian dibuat item. Setelah alat ukur selesai kemudian dilakukan tryout kepada siswa SMA. Setelah try-out dilakukan uji validitas konstruk dan reliabilitas.

Dari 44 item yang dibuat, berdasarkan uji validitas diperoleh 15 item yang valid dengan nilai korelasi berkisar dari .317 .565. Adapun hasil perhitungan uji reliabilitas dengan menggunakan alpha cronbach diperoleh bahwa koefisien reliabilitas alat ukur sense of autonomy adalah .793. Jadi dapat dikatakan bahwa alat ukur tersebut reliabel. Untuk melihat apakah terdapat perbedaan antara sebelum dan sesudah pelatihan/treatment/intervensi yang telah dilakukan maka digunakan analisis statistik uji Wilcoxon.

\section{Hasil Penelitian dan Pembahasan}

\section{Hasil Penelitian}

Berdasarkan hasil pengolahan data sebagaimana disajikan pada tabel 3 diketahui bahwa terdapat perbedaan skor sense of autonomy secara keseluruhan sebelum dan setelah pelatihan, dengan nilai $\mathrm{z}=-3.085$ dan $\mathrm{p}$-value $=.002<\alpha .05\left(\mathrm{H}_{0}\right.$ ditolak). Hal ini berarti secara keseluruhan ada perbedaan skor sense of autonomy pada sebelum dan setelah pemberian pelatihan otonomi, dan perbedaan tersebut signifikan.
Dari tabel 3 juga dapat dilihat terdapat perbedaan pada tipe amotivation, extrinsic motivation, introjected regulation, indentified regulation, dan integrated regulation, sebelum dan setelah pemberian pelatihan, dengan keseluruhan nilai $\mathrm{p}$-value $<\alpha .05$. Akan tetapi berbeda dengan aspek intrinsic motivation yang memperlihatkan nilai $\mathrm{p}$ value $(.089)>\alpha .05$ hal ini menunjukkan bahwa tidak ada perbedaan intrinsic motivation sebelum dan setelah pemberian pelatihan otonomi.

\section{Tabel 2}

Hasil Uji Beda Tipe-tipe Regulation Style Sebelum dan Setelah Pelatihan

\begin{tabular}{lcc}
\hline \multicolumn{1}{c}{ Tipe Autonomy } & $\mathrm{Z}$ & p-value \\
\hline Demotivation & -2.481 & .013 \\
Extrinsic Motivation & -4.25 & .000 \\
Introjected Regulation & -4.966 & .000 \\
Identified Regulation & -5.224 & .000 \\
Integrated Regulation & -3.722 & .000 \\
Intrinsic Motivation & -1.702 & .089 \\
Total Skor Autonomy & -3.085 & .002 \\
\hline
\end{tabular}

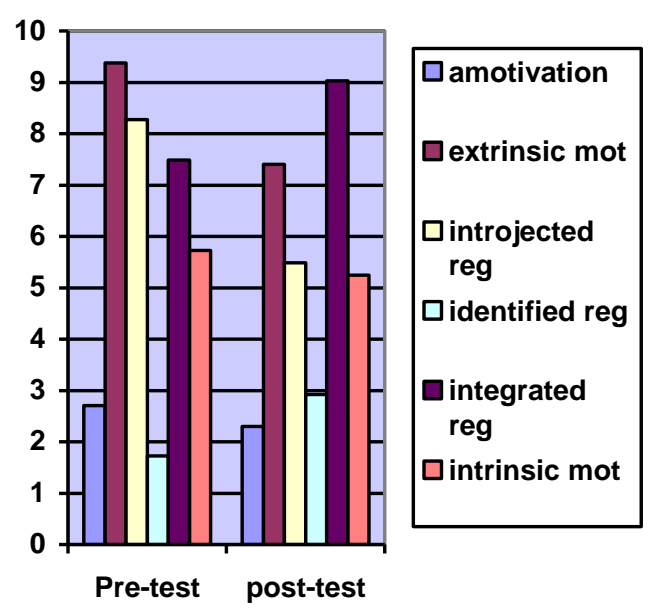

Gambar 3. Perbandingan Tipe-tipe Regulasi pada Pretest dan Posttest

Pada tipe amotivation ada perbedaan skor sebelum dan setelah pelatihan, dengan nilai $\mathrm{z}=-2.481$ dan $\mathrm{p}$-value $=.013<\alpha$ $.05\left(\right.$ Tolak $\left.\mathrm{H}_{0}\right)$. dimana perbedaan tersebut signifikan. Apabila melihat gambar 3 ada penurunan nilai amotivation setelah pelatihan. Amotivation adalah keadaan tidak ada motivasi, kondisi tidak adanya niat untuk mengatur aktivitas belajar. Adanya pelati- 
han otonomi ternyata mampu menurunkan nilai amotivation. Ini artinya pelatihan otonomi efektif menurunkan amotivation.

Pada tipe extrinsic motivation terdapat perbedaan antara skor sebelum dan sesudah pelatihan, dengan nilai $\mathrm{z}=-4.25$ dan $\mathrm{p}$ value $=.000<\alpha .05\left(\right.$ Tolak $\left.\mathrm{H}_{0}\right)$. Artinya ada perbedaan extrinsic motivation sebelum dan setelah pelatihan, dimana perbedaan tersebut signifikan. Apabila melihat gambar 3 terdapat penurunan skor extrinsic motivation setelah pelatihan. Ini artinya pelatihan otonomi efektif menurunkan extrinsic motivation.

Dari tabel 2 juga terlihat pada tipe introjected regulation terdapat perbedaan antara skor sebelum dan sesudah pelatihan, dengan nilai $\mathrm{z}=-4.966$ dan $\mathrm{p}$-value $=.000$ $<\alpha .05\left(\right.$ Tolak $\left.\mathrm{H}_{0}\right)$. Artinya ada perbedaan introjected regulation sebelum dan setelah pelatihan, dimana perbedaan tersebut signifikan. Apabila melihat gambar 3 terdapat penurunan rata-rata nilai introjected regulation sesudah pelatihan. Ini berarti pelatihan otonomi efektif menurunkan introjected regulation.

Dari tabel 2 juga terlihat pada tipe identified regulation terdapat perbedaan antara skor sebelum dan sesudah pelatihan, dengan $\mathrm{z}=-5.224$ dan $\mathrm{p}$-value $=.000<\alpha$ $.05\left(\right.$ Tolak $\left.\mathrm{H}_{0}\right)$. Artinya ada perbedaan identified regulation sebelum dan setelah pelatihan, dimana perbedaan tersebut signifikan. Apabila melihat gambar 3 terdapat peningkatan nilai/ skor otonomi setelah pelatihan. Ini berarti pelatihan otonomi efektif meningkatkan identified regulation.

Dari tabel 2 juga terlihat pada tipe integrated regulation terdapat perbedaan skor sebelum dan setelah pelatihan, dengan $\mathrm{z}=-3.722$ dan $\mathrm{p}$-value $=.000<\alpha .05$ (Tolak $\mathrm{H}_{0}$ ). Artinya ada perbedaan integrated regulation sebelum dan setelah pelatihan, dimana perbedaan tersebut signifikan. Apabila melihat gambar 3 terdapat peningkatan nilai/skor integrated regulation setelah pelatihan.

Dari tabel 2 terlihat pada aspek intrinsic motivation, tidak terdapat perbe- daan skor sebelum dan setelah pelatihan, dengan $\mathrm{z}=-1.702$ dan $\mathrm{p}$-value $=.089>\alpha$ .05 (Terima $\mathrm{H}_{0}$ ). Artinya tidak terdapat perbedaan intrinsic motivation sebelum dan sesudah pelatihan. Apabila melihat gambar 3 terdapat penurunan nilai intrinsic motivation setelah pelatihan. Namun hasil statistik di atas menunjukkan bahwa perbedaan tersebut tidak signifikan. Ini berarti pelatihan otonomi belum efektif dalam meningkatkan intrinsic motivation.

\section{Pembahasan}

Pelatihan otonomi kepada siswa memberikan pengalaman belajar bahwa siswa dapat mengubah diri menjadi lebih otonom dalam aktivitas belajar. Dari hasil penelitian terungkap bahwa terdapat dinamika proses regulasi pada siswa yang diteliti. Kondisi amotivasi menurun setelah pelatihan. Amotivation adalah keadaan tidak ada motivasi, kondisi tidak adanya niat untuk mengatur aktivitas belajar. Kondisi ini bisa saja menjadi salah satu tantangan dalam penelitian, karena sangat terikat oleh beberapa faktor yang melatarbelakanginya diantaranya adalah kesiapan dan kematangan siswa dalam mengolah dan memanfaatkan sumber daya yang mereka miliki (Cannard, LannegrandWillems, Safont-Mottay, \& Zimmermann, 2016), atau mungkin karena secara personal kondisi mereka tidak berada dalam suasana yang dipenuhi stresor psikologis yang menurunkan motivasi mereka untuk belajar (Fervaha dkk., 2014). Kedua hal tersebutlah yang berkontribusi terhadap adanya indikasi amotivasi dalam diri siswa.

Adanya pelatihan otonomi ternyata mampu menurunkan nilai amotivation. Kondisi extrinsic motivation juga menurun setelah pelatihan. Kondisi extrinsic motivation adalah kondisi dimana siswa melakukan aktivitas belajar yang didorong oleh lingkungan demi untuk mendapatkan ganjaran atau menghindari hukuman. Kondisi introjected regulation juga menurun setelah pelatihan. Kondisi introjected regulation adalah kondisi dimana siswa 
melakukan aktivitas belajar karena didorong oleh keinginan untuk memperlihatkan harga dirinya. Ini artinya pelatihan otonomi dari sesi 1 hingga sesi 12 mampu membangkitkan keinginan siswa untuk berubah menjadi lebih otonom. Dari hasil wawancara terhadap siswa diperoleh bahwa siswa senang dengan adanya pelatihan ini, jadi terpikir oleh siswa bahwa berhasil tidaknya siswa dalam bidang akademik ditentukan oleh dirinya sendiri dan bukan ditentukan oleh orang lain. Dari pelatihan yang berupa permainan-permainan (games) ini juga muncul keyakinan pada siswa bahwa ia mampu untuk berubah dan mampu menjalani perubahan tersebut, terutama adanya pengalaman mematahkan pensil dengan satu jari makin menambah keyakinan bahwa siswa mampu untuk berubah.

Secara teoretis, beberapa penelitian sebelumnya mengungkapkan bahwa peningkatan kemandirian atau autonomy dalam pribadi siswa juga tidak hanya ditentukan oleh kematangan mereka sendiri tetapi juga peran dan dukungan dari guru atau aspek lainnya yang ada di sekolah. Guru memberikan pengaruh yang luar biasa terhadap perubahan kemandirian anak salah satunya ikut serta dengan memberikan dukungan dalam sesi pelatihan tersebut (Eckes, Großmann, \& Wilde, 2018; Collie \& Martin, 2017). Sejalan dengan hal tersebut, Cheon, dan Reeve (2015) mengatakan bahwa lingkungan yang tepat termasuk peran guru dan juga kondisi kelas yang aktif dan memberikan pengaruh signifikan terhadap perubahan dalam masa pelatihan.

Pelatihan otonomi ini telah meningkatkan identified regulation. Autonomy dengan tipe identified regulation adalah suatu keadaan otonomi dimana siswa dalam mengatur aktivitas belajarnya didasarkan atau didorong oleh adanya tujuan-tujuan, dan nilai-nilai personal, serta sudah ada pengaturan diri atau regulasi diri dari yang bersangkutan meski dalam taraf ringan, yaitu siswa melakukan aktivitas belajar karena aktivitas belajar penting baginya (Griffin, 2016). Dari hasil wawancara dengan para siswa diperoleh bahwa pelatihan otonomi dari sesi 1 hingga sesi 12 semakin memberikan pemahaman berhasil tidaknya siswa dalam bidang akademik ditentukan oleh dirinya sendiri dan bukan ditentukan oleh orang lain, dan aktivitas belajar serta sekolah merupakan hal yang penting. Karena itu siswa akan mengikuti kegiatan pembelajaran di sekolah dengan baik.

Pelatihan otonomi ini juga telah meningkatkan integrated regulation. Autonomy dengan tipe integrated regulation adalah keadaan otonomi dimana siswa dalam mengatur aktivitas belajarnya ditentukan oleh dirinya sendiri, dimana ada koherensi/kesinambungan antara tujuan, nilai-nilai dan regulasi diri (Griffin, 2016). Dikatakan bahwa siswa sudah mengintegrasikan antara tujuan, nilai-nilai pribadi, dan regulasi diri dalam menentukan aktivitas belajarnya. Hasil penelitian ini menunjukkan ada peningkatan dalam integrated regulation setelah pelatihan otonomi. Ini artinya pelatihan otonomi efektif dalam meningkatkan integrated regulation. Dari hasil wawancara dengan siswa diperoleh bahwa dengan mengikuti pelatihan ini siswa menjadi semakin mantap akan pilihannya untuk melanjutkan pendidikan ke jenjang yang lebih tinggi, dan siswa memiliki keyakinan bahwa ia mampu untuk mengikuti pendidikan tinggi.

Beberapa penelitian juga yang memberikan pemahaman mengenai keberhasilan sebuah program pelatihan otonomi berpusat pada kolaborasi antara siswa dengan elemen lainnya di luar lingkup pribadi mereka khususnya yang menyajikan materi kemandirian dan kreativitas mereka (Ramdani, 2018). Marañón dan Pera (2018) mengatakan bahwa karakter otonomi ini dibangun oleh kesadaran siswa terhadap nilai profesional yang akan mereka geluti di masa depan, dengan demikian adanya pelatihan ini sangat menyangkut apa yang 
akan mereka hadapi sesuai dengan minat dan kemampuan yang mereka miliki. Selain itu pelatihan juga mengajarkan dan menanamkan nilai kepercayaan diri kepada siswa yang mengakibatkan mereka lebih leluasa dalam mengekspresikan apa yang mereka inginkan (Bolsunovskaya, Kemerova, Asadullina, Sentsov, \& Phillips, 2015). Informasi tersebut ditegaskan dalam penelitian (Bolsunovskaya dkk., 2015) yang menggambarkan autonomi siswa yang mendapatkan pelatihan kemandirian yang struktural dan memiliki tujuan yang jelas menghasilkan kolaborasi yang baik diantara aspek kognitif, afektif, dan konatif. Sehingga hal inilah yang kemudian menjadikan pelatihan tersebut menjadi lebih bermanfaat.

Dari hasil-hasil di atas, pelatihan otonomi berhasil mengubah siswa yang tadinya tidak ada motivasi atau tidak ada niat untuk mengatur diri dalam belajar dan melakukan aktivitas belajar, yang tadinya didorong atau dikendalikan oleh lingkungan di luar diri menjadi melakukan aktivitas pembelajaran karena ada tujuan, nilai-nilai pribadi dan dikendalikan oleh diri sendiri. Namun pelatihan otonomi belum berhasil meningkatkan intrinsic motivation. Mengacu kepada salah satu penelitian (Hidayat, Agustiani, \& Setyono, 2014), untuk meningkatkan intrinsic motivation dapat dilakukan melalui intervensi yang tidak hanya memfasilitasi sense of autonomy, namun perlu disertai dengan sense of competence secara simultan. Meskipun penelitian tersebut dilakukan pada subjek mahasiswa serta konteks yang lebih spesifik yaitu aktivitas membaca literatur ilmiah, namun tentunya prinsipprinsip teoretis yang telah menjadi temuan dapat pula diaplikasikan ke dalam konteks penelitian ini pada masa mendatang.

Dapat disimpulkan bahwa materi pelatihan otonomi yang telah dilakukan telah berhasil mengubah siswa yang menjadi lebih otonom dalam menjalankan aktivitas belajarnya, namun belum sampai membuat siswa memiliki intrinsic motiva- tion. Ini berarti untuk mengubah siswa menjadi memiliki motivasi intrinsik memerlukan waktu yang lebih panjang dan penambahan materi pelatihan lainnya yang dapat membangkitkan motivasi intrinsik.

\section{Simpulan dan Saran}

\section{Simpulan}

Program pelatihan otonomi efektif dalam meningkatkan tingkat otonomi siswa SMA Negeri 6 dan SMA Negeri 17. Pelatihan otonomi efektif menurunkan nilai/skor amotivation, external motivation, dan introjected regulation serta efektif meningkatkan nilai identified regulation dan integrated regulation. Selain itu pelatihan otonomi tidak efektif meningkatkan intrinsic motivation.

\section{Saran}

Berdasarkan hasil penelitian bahwa program pelatihan otonomi hanya dapat efektif mengubah kondisi amotivation siswa serta kondisi motivasi eksternal dan belum dapat mengubah intrinsic motivation, maka perlu dilakukan revisi terhadap materi pelatihan otonomi.

Revisi terhadap materi pelatihan dapat dilakukan dengan materi yang membangkitkan motivasi intrinsik dan perlu dilakukan penambahan waktu pelaksanaan pelatihan.

\section{Daftar Pustaka}

Assor, A., Roth, G., \& Deci, E. L. (2004). The emotional costs of parents' conditional regard: A selfdetermination theory analysis. Journal of Personality, 72(1), 47-88. doi.org/10.1111/j.00223506.2004.00256.x

Berk, L. (1998). Development through the life-span. Needham Heights: Allyn \& Bacon.

BPS Kementrian Pendidikan dan Kebudayaan (2014). Analisis data pendidikan untuk lembaga internasional (Analisis keuangan 
Kabupaten/ Kota tahun 2014 dan 2015).

Bolsunovskaya, L. M., Kemerova, N. S., Asadullina, L. I., Sentsov, A. E., \& Phillips, C. (2015). Promoting international students' autonomy: The experience of Tomsk Polytechnic University. Procedia - Social and Behavioral Sciences, 215(June), 5359.

doi.org/10.1016/j.sbspro.2015.11.573

Cannard, C., Lannegrand-Willems, L., Safont-Mottay, C., \& Zimmermann, G. (2016). Brief report: Academic amotivation in light of the dark side of identity formation. Journal of Adolescence, 47, 179-184. doi.org/10.1016/j.adolescence.2015.10. 002

Cheon, S. H., \& Reeve, J. (2015). A classroom-based intervention to help teachers decrease students' amotivation. Contemporary Educational Psychology, 40, 99-111. doi.org/10.1016/j.cedpsych.2014.06.00 4

Cheon, S. H., Reeve, J., Lee, Y., \& Lee, J. won. (2018). Why autonomysupportive interventions work: Explaining the professional development of teachers' motivating style. Teaching and Teacher Education, 69, 43-51. doi.org/10.1016/j.tate.2017.09.022

Cheon, S. H., Reeve, J., \& Song, Y.-G. (2016). A teacher-focused intervention to decrease pe students' amotivation by increasing need satisfaction and decreasing need frustration. Journal of Sport and Exercise Psychology, 38(3), 217-235. doi.org/10.1016/S00960217(15)34710-5

Collie, R. J., \& Martin, A. J. (2017). Teachers' sense of adaptability: Examining links with perceived autonomy support, teachers' psychological functioning, and students' numeracy achievement. Learning and Individual Differences,
55 , $29-39$. doi.org/10.1016/j.lindif.2017.03.003

Eckes, A., Großmann, N., \& Wilde, M. (2018). Studies on the effects of structure in the context of autonomysupportive or controlling teacher behavior on students' intrinsic motivation. Learning and Individual Differences, 62(April 2017), 69-78. doi.org/10.1016/j.lindif.2018.01.011

Fervaha, G., Zakzanis, K. K., Jeffay, E., Graff-Guerrero, A., Foussias, G., Agid, O., \& Remington, G. (2014). Amotivation as central to negative schizotypy and their predictive value for happiness. Personality and Individual Differences, 68, 37-42. doi.org/10.1016/j.paid.2014.03.039

Griffin, B. W. (2016). Perceived autonomy support, intrinsic motivation, and student ratings of instruction. Studies in Educational Evaluation, 51, 116125.

doi.org/10.1016/j.stueduc.2016.10.007

Halimah, L., Kusdiyati, S., \& Susandari, S. (2017). Pengaruh konteks teman sebaya terhadap keterlibatan belajar dengan mediator self-system processes. Psympathic: Jurnal Ilmiah Psikologi, 4(2), 265. doi.org/10.15575/psy.v4i2.1612

Hidayat, I. N., Agustiani, H., \& Setyono, I. L. (2014). Rancangan program pelatihan exercise membaca untuk meningkatkan motivasi intrinsik membaca literatur ilmiah pada mahasiswa. (Tesis tidak dipublikasikan). Universitas Padjadjaran, Fakultas Psikologi,

Legault, L. (2016). The need for autonomy. Dalam V. Zeigler-Hill, T.K. Shackelford (eds). Encyclopedia of Personality \& Individual Differences. DOI 10.1007/948-3-319-280998_11201-1

Marañón, A. A., \& Pera, M. P. I. (2018). Confusion about professional autonomy among final-year nursing students in Spain. Journal of 
Professional Nursing, (July), 1-6. doi.org/10.1016/j.profnurs.2018.07.008

Ramdani, Z. (2018). Kolaborasi antara kepala sekolah, guru dan siswa dalam menciptakan sistem pendidikan yang berkualitas. National Conference on Educational Assessment and Policy.

Ryan, R., \& Deci, E. (2000). Intrinsic and extrisix motivations: Classic definitions and new directions. Contemporary Educational Psychology, 25, 54-67. doi.org/10.1006/ceps.1999.1020

Ryan, R. M., \& Deci, E. L. (2002). Overview of self-determination theory: An organismic dialectical perspective. In R. M. Ryan, \& E. L. Deci, Handbook of self-determination research (pp. 1 - 31). New York: University of Rochester Press.

Spear, H. J., \& Kulbok, P. (2004). Autonomy and adolescence: A concept analysis. Public Health Nursing, 21(2), 144-152. doi.org/10.1111/j.07371209.2004.021208.x

Su, Y. L., \& Reeve, J. (2011). A metaanalysis of the effectiveness of intervention programs designed to support autonomy. Educational Psychology Review, 23(1), 159-188. doi.org/10.1007/s10648-010-9142-7

Wehmeyer, M. L., \& Shogren, K. A. (2016). Autonomy-supportive interventions: Promoting self- determined learning. International Journal of Psycho-Educational Seciences, 5(2).

Wexley, K. N., Sanders, R. E., \& Yukel, G. A. (1973). Training interviewers to eliminate contrast effects in employment interviews. Journal of Applied Psychology, 57(3), 233-236. doi.org/10.1037/h0034714 